\title{
Changes in Dietary lodine Explains Increasing Incidence of Breast Cancer with Distant Involvement in Young Women
}

\author{
Jay Rappaport ${ }^{\bowtie}$ \\ Department of Neuroscience, Lewis Katz School of Medicine Temple University. \\ $\triangle$ Corresponding author: Department of Neuroscience, Lewis Katz School of Medicine, Temple University, 3500 N. Broad St., Medical Education and Research \\ Bld., Rm. 760, Philadelphia, PA, USA, 19140. Email: jayrapp@temple.edu; Phone: 215-707-6248; Fax: 215-707-4888. \\ (c) Ivyspring International Publisher. This is an open access article distributed under the terms of the Creative Commons Attribution (CC BY-NC) license \\ (https://creativecommons.org/licenses/by-nc/4.0/). See http://ivyspring.com/terms for full terms and conditions.
}

Received: 2016.10.06; Accepted: 2016.12.03; Published: 2017.01.13

The incidence of breast cancer with distant involvement at diagnosis is increasing in young women, age 25-39, possibly at an accelerating rate, as previously demonstrated by Johnson et al. ${ }^{1}$ This disturbing trend was also observed in women age 40-54, albeit to a letter extent. Understanding the causes for these changes in cancer demographics is particularly important in view of the young age of these women, as well as the poor survival rate for women with distant metastatic breast disease. There have been explanations proposed in several letters, including vaccination 2, advanced-age at first pregnancy 3 as well as folate supplementation 4, however these explanations have not been particularly satisfying. In response, the original authors ${ }^{5}$ suggested causal association need explain: 1 ) why a proposed agent or risk factor would cause advanced disease, 2) why it would preferentially affect the youngest women, and 3) how temporal trends in the proposed causative agent have changed since the mid-1970s ${ }^{5}$. The hypothesis that iodine deficiency in the United States, plays a role in the increased incidence of breast cancer with distant involvement, is discussed here in the context of these three factors.

1) Pathogenesis: Iodine deficiency has been proposed to play a causative role in the development of breast cancer 6, 7. Dietary iodine has also been previously proposed to play a protective role in breast cancer 8 , to a large degree based on the increased iodine consumption of dietary iodine in Japanese women, having and exceptionally low incidence of breast cancer ${ }^{9}$. Furthermore, emigration of Japanese women ${ }^{10}$ and adopting a western diet ${ }^{11}$ is associated with higher breast cancer rates. Iodine is taken up by the sodium/iodide symporter in the breast and its role is important in promoting the development of normal versus neoplastic breast tissue development ${ }^{12}$. In animal models of breast cancer, iodine in supplement or seaweed form, has demonstrated beneficial effects in suppressing breast cancer cell and tumor growth ${ }^{12}$. The mechanism of action of iodine's anticancer effect may be complex, and roles as an antioxidant, promoting differentiation and apoptosis related to breast cancer have been proposed ${ }^{13}$.

Iodine deficiency is an important cause of thyroid deficiency; the potential linkage between thyroid disease and breast cancer has been a matter of considerable interest $7,14-16$ and has been extensively reviewed $17-20$. In contrast, one study suggested hypothyroidism actually reduces the risk of breast cancer 21, however, this study was done in older, mostly postmenopausal women and thus, this conclusion may not be relevant to the population of younger women (age 25-39) at risk for increased invasive breast cancer discussed here. Studies implanting human breast cancer as well as hepatocellular carcinoma cells in nude mice demonstrate that hypothyroidism reduces tumor growth, but at the same time enhances invasiveness and metastasis ${ }^{22}$. These findings provide a potential explanation for increased distant breast tumors at time of diagnosis. Since iodine deficiency is a major cause of hypothyroidism, breast cancer with distant 
metastasis may be promoted in part by reduced thyroid function, where slower tumor growth (precluding earlier diagnosis), yet increased invasiveness could be consequential. Iodine deficiency, therefore, may contribute to breast cancer and its progression directly within breast tissue, and secondarily by decreased thyroid function leading to metastasis. The importance of iodine in breast cancer is further emphasized by the adjuvant effects of iodine $\left(\mathrm{I}_{2}\right)$ supplementation in combination with doxorubixin for breast cancer treatment ${ }^{23}$. In these studies, iodine treatment resulted in reduced tumor size and proliferating cell nuclear antigen (PCNA) expression.

2) Population Iodine Deficiency: Increased iodine demand in women is likely due to the increased uptake of iodine in breast tissue, in addition to the thyroid gland, where iodine plays a role in the development and maintenance of healthy breast tissue (expanding after puberty) and in breast remodeling during lactation, and pregnancy ${ }^{12}$. Young women and to a greater extent pregnant women, have lower urinary iodine levels than men of similar age. According to the CDC's 2012 Second National Report of Biochemical Indicators of Diet and Nutrition in the U.S. Population (www.cdc.gov/nutritionreport/report.html), women of childbearing age exhibited the lowest urinary iodine levels of any age group.

Iodine deficiency is associated with fibrocystic breast disease, which can be effectively treated or prevented with iodine supplementation ${ }^{24}$. Fibrocystic breast disease affects at least $50 \%$ of women of child-bearing age and is associated with an increased risk of developing breast cancer ${ }^{25}$. In women with atypia, there was twice the risk of developing breast cancer among women under age 45 in this study, relative to women age 55 or older, possibly reflecting a relationship between hormonal considerations and cancer risk. While the issue of metastasis was not investigated in this study, the increased risk in developing cancer in the ipsilateral and contralateral breast tissue might suggest metastasis or alternatively the presence of cancerous precursors as proposed by the authors. A previous study demonstrated atypia among the consequences of iodine deficiency in human and animal models ${ }^{26}$.

Studies in rats have previously demonstrated that iodine deficiency results in "hyperresponsiveness" to estradiol, resulting in increased alveolar cell proliferation, abnormal changes within nuclei, and increased uptake of iodine within vacuoles, in estradiol stimulated mammary glands ${ }^{27}$. These aforementioned studies provide a potential basis for the increased iodine requirements for women of childbearing age, as well as the predisposition of this age group to the development of breast cancer.

Whether fibrocystic breast disease leads to metastatic breast disease at diagnosis is unclear, however, fibrocystic changes appear to be prognostically significant in patients with small, node-negative invasive breast cancer ${ }^{28}$. The average age of women in this study was older, so it remains unclear if an increased risk for metastatic breast cancer can be attributed to previous fibrocystic breast disease in the age group (20-39) discussed. Nevertheless, the prognostic association of fibrocystic breast disease with metastatic breast cancer, as well as the association of fibrocystic breast disease with premenopausal women provides a plausible mechanism for disease progression.

3) Temporal Changes in Body Iodine: Comparisons of the National Health and Nutrition Examination Surveys (NHANES) showed a significant decrease in urinary iodine levels in the overall population during the period 1988-1994 as compared to the period 1971-1974 ${ }^{29}$. The initial urinary iodine levels (median $320 \mu \mathrm{g} / \mathrm{L}$ ) were reduced by more than half during the period 1988-1994 (median $145 \mu \mathrm{g} / \mathrm{dl} ; \mathrm{P}<0.0001$ ). Accordingly, the percentage of total persons with iodine deficiency, (below $50 \mu \mathrm{g} / \mathrm{L}$ ), increased from 2.6\% during the period $1971-1974$, to $14.5 \%$ in $1988-1994$, representing a 5.6-fold increase ${ }^{29}$. Females showed a higher frequency of iodine deficiency than males (15.1 versus $8.1 \%$ ) with lower median iodine levels for females. For young women of child bearing age, age 15-44, there was a 3.8-fold increase in iodine insufficiency, with a 6.9-fold increase in the number of pregnant women also fitting this definition 29 .

Blacks had lower levels of iodine than whites during both time periods (1971-1974 and 1988-1994) ${ }^{29}$. During the period 2003-2006, blacks continued to exhibit lower urinary iodine levels than whites, with black women in the 20-39 age group having the lowest geometric mean levels of urinary iodine (www.cdc.gov/nutritionreport/report.html). Iodine deficiency is defined as levels below $50 \mu \mathrm{g}$ iodine/liter urine or adjusted for creatinine, UI/Cr), where UI/Cr $<50 \mu \mathrm{g} / \mathrm{g}$ creatinine is considered deficient. During this period 2003-2006, the geometric means of UI/Cr in white and back women in this age group was 128 (116-142, 95\% confidence interval) and 74.9 (64.2-87.5), respectively. Lower UI levels in black relative to white women may also explain the greater increase in frequency of distant breast cancer in black women, as well as the growing health disparities gap ${ }^{30}$. More recent studies including data between 2009 and 2014 demonstrate that breast cancers among black and white women with distant disease in the under- 40 age 
group continue to increase ${ }^{31}$. Black women remain at greater risk for breast cancer with distant disease, relative to white women or all women combined, and furthermore, the annual percentage increase of such cases among black women is larger (almost double that of white women) ${ }^{31}$

According to the nutritional survey reports during the period 2005-2008, pregnant women had median urinary iodine levels of $125 \mu \mathrm{g} /$ liter, and 56.9 percent had levels less than the 150-249 $\mu \mathrm{g} /$ liter urinary iodine recommended by the World Health Organization ${ }^{32}$. Thus, although potentially stabilized, the inadequate iodine levels observed in young women persists, with black women and pregnant women especially at risk. In addition to the potential risk for breast cancer, even mild iodine insufficiency appears to correlate with neurocognitive impairments in children ${ }^{33}$. Thus, iodine insufficiency represents a major health issue for women of childbearing age as well as developing fetuses.

The observed drop in urinary iodine in young women as well as in the general population, since the 1970s, is presumably due to removal of iodine from bread and substitution with bromine as flour conditioner during this period of time, due in a large part to previous concerns about excess iodine as well as the preferences of commercial bakers for brominated flour. Bromine, a suspected carcinogen, may further exacerbate iodine insufficiency since bromine competes for iodine uptake by the thyroid gland ${ }^{34}$ and potentially other tissues (i.e. breast).

The annual increase in distant breast cancer diagnosis since the mid-1970s may reflect the time of exposure to decreased iodine and increased dietary bromine. Studies in countries where brominated flour and brominated vegetable oil are banned (i.e. the Canada and the European Union), may not necessarily show parallel increases in metastatic breast cancer in young women as occurring in the United States. New U.S. Government Dietary Recommendations (January $7^{\text {th }}$ 2016) may also have impact since reduction in dietary salt intake from 3,440 to $2,300 \mathrm{mg}$ per day may further reduce the intake of iodine from iodized salt. Such recommendations for universal salt restriction (i.e. for the benefit of salt-sensitive hypertension), should be balanced with the iodine needs of young women of childbearing age, particularly black women, to support breast and thyroid health, potentially cancer prevention, and the needs of the developing fetus during pregnancy.

In conclusion, dietary iodine insufficiency represents a plausible explanation for the increasing incidence of breast cancer in young women with distant metastasis. In view of the established reduction in iodine levels in US women of childbearing age since the mid 70s, this group would be most vulnerable to increased breast cancer risk. The increased sensitivity of breast tissue to estradiol induced proliferative changes in the setting of dietary iodine insufficiency, provides a plausible mechanistic explanation for the increasing incidence of breast cancer with distant involvement in this age group. Based on the importance of iodine in thyroid and breast health, fetal brain development, as well as deficits in nutritional trends among younger women, iodine testing and management may be considered as a potentially important aspect for clinical practice.

\section{Competing Interests}

The author has declared that no competing interest exists.

\section{References}

1. Johnson RH, Chien FL, Bleyer A. Incidence of breast cancer with distant involvement among women in the United States, 1976 to 2009. JAMA. 2013;309: 800-805.

2. Cramer DW, Finn OJ. Incidence rate of breast cancer in young women. JAMA. 2013;309: 2434-2435.

3. Hou N, Huo D. Incidence rate of breast cancer in young women. JAMA. 2013;309: 2433.

4. Goldstein MR, Mascitelli L. Incidence rate of breast cancer in young women. JAMA. 2013;309: 2434.

5. Johnson $\mathrm{RH}$, Chien FL, Bleyer A. Incidence rate of breast cancer in young women--reply. JAMA. 2013;309: 2435-2436.

6. Eskin BA. Iodine metabolism and breast cancer. Trans N Y Acad Sci. 1970;32: 911-947.

7. Stadel BV. Dietary iodine and risk of breast, endometrial, and ovarian cancer. Lancet. 1976;1: 890-891.

8. Cann SA, van Netten JP, van Netten C. Hypothesis: iodine, selenium and the development of breast cancer. Cancer Causes Control. 2000;11: 121-127.

9. Parkin DM, Pisani P, Ferlay J. Estimates of the worldwide incidence of 25 major cancers in 1990. Int J Cancer. 1999;80: 827-841.

10. LeMarchand L, Kolonel LN, Nomura AM. Breast cancer survival among Hawaii Japanese and Caucasian women. Ten-year rates and survival by place of birth. Am J Epidemiol. 1985;122: 571-578.

11. Minami Y, Takano A, Okuno Y, Fukao A, Kurihara M, Hisamichi S. Trends in the incidence of female breast and cervical cancers in Miyagi Prefecture, Japan, 1959-1987. Jpn J Cancer Res. 1996;87: 10-17.

12. Aceves $C$, Anguiano B, Delgado G. Is iodine a gatekeeper of the integrity of the mammary gland? J Mammary Gland Biol Neoplasia. 2005;10: 189-196.

13. Aceves C, Anguiano B, Delgado G. The extrathyronine actions of iodine as antioxidant, apoptotic, and differentiation factor in various tissues. Thyroid. 2013;23: 938-946

14. Adamopoulos DA, Vassilaros S, Kapolla N, Papadiamantis J, Georgiakodis F, Michalakis A. Thyroid disease in patients with benign and malignant mastopathy. Cancer. 1986;57: 125-128.

15. Turken O, NarIn Y, DemIrbas S, et al. Breast cancer in association with thyroid disorders. Breast Cancer Res. 2003;5: R110-113.

16. Smyth PP, Smith DF, McDermott EW, Murray MJ, Geraghty JG, O'Higgins NJ. A direct relationship between thyroid enlargement and breast cancer. J Clin Endocrinol Metab. 1996;81: 937-941.

17. Goldman MB. Thyroid diseases and breast cancer. Epidemiol Rev. 1990;12: 16-28.

18. Shering SG, Zbar AP, Moriarty M, McDermott EW, O'Higgins NJ, Smyth PP. Thyroid disorders and breast cancer. Eur J Cancer Prev. 1996;5: 504-506.

19. Smyth PP. The thyroid and breast cancer: a significant association? Ann Med. 1997;29: 189-191.

20. Smyth PP. The thyroid, iodine and breast cancer. Breast Cancer Res. 2003;5: 235-238.

21. Cristofanilli M, Yamamura $\mathrm{Y}, \mathrm{Kau}$ SW, et al. Thyroid hormone and breast carcinoma. Primary hypothyroidism is associated with a reduced incidence of primary breast carcinoma. Cancer. 2005;103: 1122-1128.

22. Martinez-Iglesias O, Garcia-Silva S, Regadera J, Aranda A. Hypothyroidism enhances tumor invasiveness and metastasis development. PLoS One. 2009;4: e6428.

23. Alfaro Y, Delgado G, Carabez A, Anguiano B, Aceves C. Iodine and doxorubicin, a good combination for mammary cancer treatment: 
antineoplastic adjuvancy, chemoresistance inhibition, and cardioprotection. Mol Cancer. 2013;12: 45.

24. Ghent WR, Eskin BA, Low DA, Hill LP. Iodine replacement in fibrocystic disease of the breast. Can J Surg. 1993;36: 453-460.

25. Hartmann LC, Sellers TA, Frost MH, et al. Benign breast disease and the risk of breast cancer. N Engl J Med. 2005;353: 229-237.

26. Eskin BA. Iodine and mammary cancer. Adv Exp Med Biol. 1977:91: 293-304.

27. Strum JM. Effect of iodide-deficiency on rat mammary gland. Virchows Arch B Cell Pathol Incl Mol Pathol. 1979;30: 209-220.

28. Durak MG, Gonzalez-Angulo AM, Hanrahan EO, et al. Age and associated fibrocystic changes are prognostically significant in patients with small node-negative (T1a,bN0) invasive breast cancer. Breast J. 2011;17: 462-469.

29. Hollowell JG, Staehling NW, Hannon WH, et al. Iodine nutrition in the United States. Trends and public health implications: iodine excretion data from National Health and Nutrition Examination Surveys I and III (1971-1974 and 1988-1994). J Clin Endocrinol Metab. 1998;83: 3401-3408.

30. Tehranifar $\mathrm{P}$, Akinyemiju TF, Terry MB. Incidence rate of breast cancer in young women. JAMA. 2013;309: 2433-2434.

31. Richardson LC, Henley SJ, Miller JW, Massetti G, Thomas CC. Patterns and Trends in Age-Specific Black-White Differences in Breast Cancer Incidence and Mortality - United States, 1999-2014. MMWR Morb Mortal Wkly Rep. 2016;65: 1093-1098.

32. Caldwell KL, Makhmudov A, Ely E, Jones RL, Wang RY. Iodine status of the U.S. population, National Health and Nutrition Examination Survey, 2005-2006 and 2007-2008. Thyroid. 2011;21: 419-427.

33. Bath SC, Steer CD, Golding J, Emmett P, Rayman MP. Effect of inadequate iodine status in UK pregnant women on cognitive outcomes in their children: results from the Avon Longitudinal Study of Parents and Children (ALSPAC). Lancet. 2013;382: 331-337.

34. Vobecky M, Babicky A, Lener J, Svandova E. Interaction of bromine with iodine in the rat thyroid gland at enhanced bromide intake. Biol Trace Elem Res. 1996;54: 207-212. 